\title{
High-value Utilization of Citrus Peel: Efficient Extraction of Essential Oil and Preparation of Activated Carbon
}

\author{
Jie Weng, ${ }^{a}$ Mi-Mi Wei, ${ }^{\text {a }}$ Shao-Ji Wu, ${ }^{\text {a }}$ Yun-Quan Liu, ${ }^{\text {a }}$ Shui-Rong Li, ${ }^{\text {a }}$ Yue-Yuan Ye, ${ }^{\text {a }}$ \\ Meng Wang, ${ }^{\mathrm{b}}$ and Duo Wang ${ }^{\mathrm{a}, *}$
}

This paper describes the high-value utilization of citrus peel waste, in which potassium carbonate $\left(\mathrm{K}_{2} \mathrm{CO}_{3}\right)$ was used to assist the extraction of essential oils and served as the activating agent for the further preparation of activated carbons. A common alkali metal salt, $\mathrm{K}_{2} \mathrm{CO}_{3}$, was confirmed to be effective in promoting the extraction of essential oils from citrus peel. Compared to the $2.4 \mathrm{wt} \%$ extraction rate of essential oils obtained using regular steam distillation, a $6.2 \mathrm{wt} \%$ extraction rate was achieved when the citrus peel was pretreated with a $\mathrm{K}_{2} \mathrm{CO}_{3}$ solution. Meanwhile, its chemical composition remained stable, indicating that these additional essential oils can also be directly used in areas that have already been developed in the perfume industry. The solid residue collected after essential oil extraction was further used as the precursor for activated carbons. The specific surface area of activated carbons reached up to $1846 \mathrm{~m}^{2} / \mathrm{g}$ at a carbonization temperature of $800^{\circ} \mathrm{C}$, and it exhibited a highly developed microporous structure.

Keywords: Essential oil; Activated carbon; Citrus peel; $\mathrm{K}_{2} \mathrm{CO}_{3}$

Contact information: a: College of Energy, Xiamen University, Xiamen, Fujian, China 361102; b: Key Laboratory of Plant Nutrition and Fertilizer, Ministry of Agriculture/Institute of Agricultural Resources and Regional Planning, Chinese Academy of Agricultural Sciences, Beijing, China 100081;

*Corresponding author: duowang@xmu.edu.cn

\section{INTRODUCTION}

Citrus fruits are one of the most abundant crops worldwide, with an annual output of over 115.5 million tons in 2012 (Ledesma-Escobar and Luque de Castro 2014). About 48.2 million tons of citrus are industrially processed for the production of juice (Lohrasbi et al. 2010). Citrus peel waste accounts for almost of $50 \%$ of the wet fruit mass (RomeroCano et al. 2016). The efficient utilization of citrus peels is thus essential for environmental protection. Several approaches for the utilization of citrus peels have been developing rapidly, such as essential oil extraction (Bustamante et al. 2016), activated carbon preparation (Foo and Hameed 2012), pectin separation (Sharma et al. 2017), and as biosorption material for heavy metals (Santos et al. 2015). However, these technologies are still not extensively used due to several drawbacks. For instance, the essential oil yield only reached $1.30 \%$ with a hydro-distillation technology (Yen and Lin 2017), and only $1.54 \%$ with a microwave-assisted steam distillation method (Farhat et al. 2011). The residual material after the extraction of essential oil must be properly treated because it can cause environmental pollution.

Essential oils derived from citrus peels can be used in various fields, including the cosmetic, perfume, food, and pharmaceutical industries (Uysal et al. 2011; Allaf et al. 
2013; Acar et al. 2015). Because of its use of simple facilities, hydro-distillation is extensively utilized in the industry for the extraction of essential oil; however, it is not easy to obtain a high yield of essential oil based on this traditional method. To achieve a higher essential oil yield, researchers have developed various technologies, such as microwaveassisted hydro-distillation (Farhat et al. 2011) and supercritical $\mathrm{CO}_{2}$ extraction (Mouahid et al. 2017). However, a great deal of energy is consumed in these extraction processes, which makes it difficult to be widely used. In this work, a certain amount of potassium carbonate $\left(\mathrm{K}_{2} \mathrm{CO}_{3}\right)$ was mixed with citrus peels in a traditional hydro-distillation process, which remarkably improved the yield of essential oils. Meanwhile, the chemical composition of essential oils was almost unchanged. The solid residue collected after the extraction of essential oil was further used as the precursor for activated carbons.

The use of citrus peels as the precursor for activated carbons has attracted increasing attention in recent years. Activated carbon is prepared through carbonizing raw peels at a high temperature with physical or/and chemical activator. Physical activation has an advantage in terms of energy consumption (for example, activation with steam could reduce the temperature and time), while chemical activation enables more effective control of physico-chemical characteristics of activated carbons. Activated carbons can be used as adsorbents, catalyst support, and electrode materials (Dhelipan et al. 2017; Tovar et al. 2019). Tovar et al. (2019) prepared activated carbons from the remnant residue after pectin extraction activated by phosphoric acid $\left(\mathrm{H}_{3} \mathrm{PO}_{4}\right)$, which exhibited $2343 \mathrm{mg} / \mathrm{g}$ of the adsorption capacity for methyl orange. However, most chemical activating agents such as zinc chloride $\left(\mathrm{ZnCl}_{2}\right)$, potassium hydroxide $(\mathrm{KOH})$ are harmful to the surrounding environment because they are highly corrosive. As a kind of food additive (Xiao et al. 2012), $\mathrm{K}_{2} \mathrm{CO}_{3}$ is relatively eco-friendly because it has weak corrosion and nontoxicity. It has also been verified as an effective activating agent for activated carbon preparation. Considering that the catalytic effect of potassium on steam gasification (Dupont et al. 2016), the activating process can be carried out at lower temperature. Therefore, the common alkali metal salt, $\mathrm{K}_{2} \mathrm{CO}_{3}$, was chosen as a candidate for both essential oil extraction and activated carbon preparation in this study. Based on this hypothesis, a high essential oil yield of $6.2 \mathrm{wt} \%$ was achieved; meanwhile, the specific surface area of the activated carbons reached up to $1846 \mathrm{~m}^{2} / \mathrm{g}$ and exhibited a highly developed microporous structure.

\section{EXPERIMENTAL}

\section{Materials}

The navel orange (Citrus sinensis) used in this study were extensively cultivated in Yunnan, China.

Table 1. Proximate and Ultimate Analysis of Citrus Peels

\begin{tabular}{|c|c|c|c|c|c|c|c|c|c|c|}
\hline \multicolumn{4}{|c|}{ Elemental Analysis (wt\%) } & \multicolumn{4}{c|}{ Proximate Analysis (wt\%) } & \multicolumn{2}{c|}{$\begin{array}{c}\text { Physical } \\
\text { Properties }\end{array}$} \\
\hline C & H & O* & N & S & Moisture & $\begin{array}{c}\text { Volatile } \\
\text { Matter }\end{array}$ & Ash & $\begin{array}{c}\text { Fixed } \\
\text { Carbon }\end{array}$ & $\begin{array}{c}S_{\mathrm{BET}} \\
\left(\mathrm{m}^{2} / \mathrm{g}\right)\end{array}$ & $\begin{array}{c}V_{\mathrm{t}} \\
\left(\mathrm{cm}^{3} / \mathrm{g}\right)\end{array}$ \\
\hline 41.87 & 5.49 & 51.62 & 0.58 & 0.50 & 9.80 & 73.61 & 2.86 & 13.73 & 1.32 & 0.0009 \\
\hline
\end{tabular}

${ }^{*}$ Determined by difference 
Prior to use, the peels were first washed with tap water and deionized water several times to remove dirt from the surface. Then, the peels were cut into the particle size of 8 to $10 \mathrm{~mm}$. The proximate and ultimate analyses of the dry citrus peels are shown in Table 1.

\section{Experimental Apparatus}

A schematic diagram of the experimental system is shown in Fig. 1. It was composed of two subsystems: (1) the extraction unit of essential oils, in which the extraction conditions were studied, and (2) the preparation unit of activated carbons, in which activated carbons were prepared in various activation conditions.

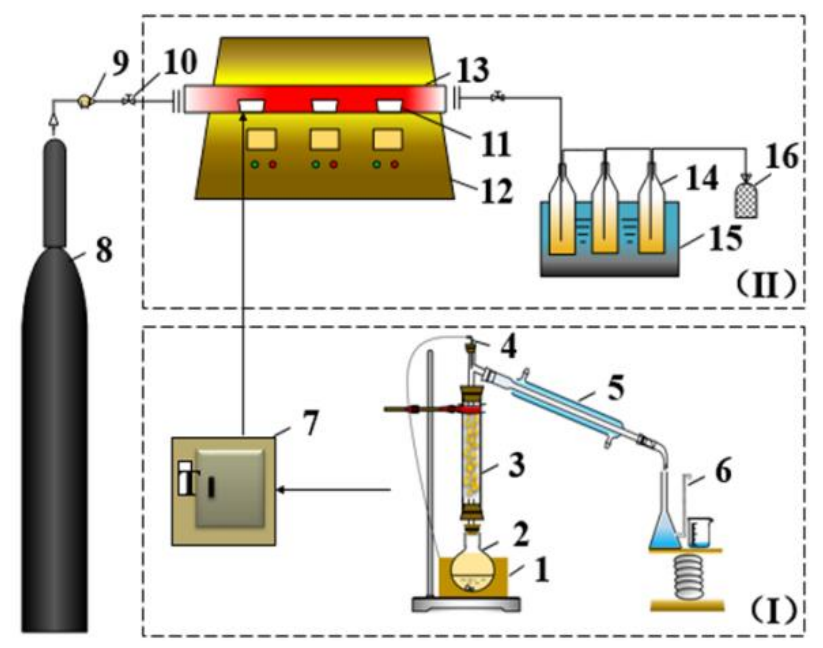

Fig. 1. Schematic diagram of the experimental system (1- heating mantle; 2 - flask; 3- fixed bed extractor; 4- thermocouple; 5- condenser; 6- essential oils collector; 7- drying oven; 8- nitrogen gas tank; 9- flow meter; 10- switching valve; 11- corundum boat; 12 - furnace; 13 - quartz tube reactor; 14- liquid collector; 15- cooling installation; and 16- non-condensable gas collecting bag)

\section{Methods}

Essential oil extraction

The $\mathrm{K}_{2} \mathrm{CO}_{3}$ solution $(250 \mathrm{~mL}$ ) with different concentrations (50 to $200 \mathrm{~g} / \mathrm{L}$ at steps of $50 \mathrm{~g} / \mathrm{L}$ ) was first prepared in a 500-mL beaker, and named as $\mathrm{KC} 1$ to $\mathrm{KC} 4$, respectively. The $\mathrm{K}_{2} \mathrm{CO}_{3}$ solution was then transferred into another 500 -mL beaker containing $160 \mathrm{~g}$ of citrus peels, which was slowly stirred for $15 \mathrm{~min}$. The impregnated peels were filtered and placed in the fixed bed extractor. The steam distillation device provided a constant flow of steam at a specific rate of $0.019 \mathrm{~kg} / \mathrm{min} / \mathrm{m}^{2}$ to the fixed bed extractor by means of adjusting the power of the heating mantle. In each run, the produced steam gradually flowed into the extractor and entrained the essential oil from the raw citrus peels into the condenser. Most of the essential oils and steam were condensed and collected in the essential oil collector. The obtained essential oil was dried with anhydrous sodium sulphate and stored at $4{ }^{\circ} \mathrm{C}$ until further use. The yield of essential oil was calculated as a percentage (wt\%):

$$
\text { Yield }(\%)=\text { Weight of essential oil }(\mathrm{g}) / \text { the weight of dry citrus peel }(\mathrm{g}) * 100
$$

The essential oil obtained from the raw citrus peels was referred to as EO-CP. The four kinds of residual citrus peels with different $\mathrm{K}_{2} \mathrm{CO}_{3}$ impregnation ratios were further dried at $105^{\circ} \mathrm{C}$ for $24 \mathrm{~h}$ and were known as $\mathrm{CP}-\mathrm{KC} 1, \mathrm{CP}-\mathrm{KC} 2, \mathrm{CP}-\mathrm{KC} 3$, and $\mathrm{CP}-\mathrm{KC} 4$. As 
a blank control, the raw citrus peel only treated by steam distillation was known as CP-SD. Another pretreated peel was referred to as $\mathrm{KC}-\mathrm{NP}$, and its pretreatment process was the same as that of CP-KC3 but without the essential oil extraction.

\section{Activated carbon preparation}

The carbonization of citrus peels was performed in a solid tube furnace (GWL1400; Juxing Yaolu, Henan, China) that was equipped with three independent temperature controllers and had a maximum working temperature of $1400{ }^{\circ} \mathrm{C}$. The solid residue collected after the essential oil extraction was first ground and sieved to the particle size of 40-mesh. Then, the pretreated peels loaded on a corundum boat were placed inside a quartz, 6-cm diameter and 130-cm-long tubular reactor (Keda Quartz, Jiangsu, China). In a typical experiment, $5 \mathrm{~g}$ of citrus peels was heated up to $800{ }^{\circ} \mathrm{C}$ at a $10{ }^{\circ} \mathrm{C} / \mathrm{min}$ heating rate and held for $60 \mathrm{~min}$ at that temperature. Dinitrogen $\left(\mathrm{N}_{2}\right)$ with a flow rate of $200 \mathrm{~mL} / \mathrm{min}$ was adopted to achieve an anoxic atmosphere. After the furnace was cooled to room temperature, the resultant activated carbon was collected and flushed several times with 1 $\mathrm{mol} / \mathrm{L} \mathrm{HCl}$ solution and deionized water until the $\mathrm{pH}$ became neutral. The washed activated carbon was oven-dried at $110{ }^{\circ} \mathrm{C}$ for $12 \mathrm{~h}$. The activated carbons derived from the carbonization of raw citrus peel CP-SD, CP-KC1, CP-KC2, CP-KC3, CP-KC4, and KC$\mathrm{NP}$ were known as Char-CP, Char-SD, AC-KC1, AC-KC2, AC-KC3, AC-KC4, and AC$\mathrm{KC}-\mathrm{NP}$, respectively. The yield of activated carbons was calculated as a percentage $(\%)$ according to Eq. 2:

$$
\text { Yield }(\%)=\text { Weight of activated carbon }(\mathrm{g}) / \text { Weight of precursor }(\mathrm{g}) * 100
$$

The volatiles produced in the carbonization process entered the downstream condensation system, which consisted of three $250-\mathrm{mL}$ flasks in series dipped into a container filled with isopropyl to maintain a temperature of $-15{ }^{\circ} \mathrm{C}$. The condensable components in the volatiles were quenched and collected in the flask. After the experiments, the liquid that had collected in the flasks and the activated carbons remaining in the boat were quantified by weight. The gaseous product was determined by taking the difference.

\section{Physico-chemical characterization}

The chemical compositions of the essential oils and the liquid phase collected during the carbonization process were analyzed using a gas chromatography/mass spectrometer (GC/MS; QP2010 SE; Shimadzu, Kyoto, Japan) equipped with a Rtx-5MS capillary column $(30 \mathrm{~mm} \times 0.25 \mathrm{~mm}$ i.d. $\times 0.25-\mu \mathrm{m}$ film thickness $)$ The $\mathrm{N}_{2}$ adsorption/desorption isotherms for citrus peels and activated carbons at $77 \mathrm{~K}$ were obtained using an ASAP 2020 instrument (Micromeritics, Norcross, GA, USA). Prior to analysis, all of the samples were degassed at $300{ }^{\circ} \mathrm{C}$ for $4 \mathrm{~h}$ under vacuum $(0.1 \mathrm{~atm})$. The Brunauer-Emmett-Teller $(\mathrm{BET})$ surface area $\left(S_{\mathrm{BET}}\right)$ values were measured using the BET equation to the relative pressure range $\left(\mathrm{p} / \mathrm{p}^{\circ}\right)$ of 0.05 to 0.20 . The total pore volume $\left(V_{\mathrm{t}}\right)$ was estimated from the maximum amount of $\mathrm{N}_{2}$ adsorbed at a relative pressure $\mathrm{P} / \mathrm{P}_{0}$ of 0.95 based on the Gurvich rule, while the micropore surface area and micropore volume were determined using the t-plot method. The mean pore width was calculated from the relation $4 \mathrm{~V}_{\mathrm{t}} / \mathrm{S}_{\mathrm{BET}}$. A transmission electron microscope (TEM; JEM 2010; JEOL Ltd., Tokyo, Japan) and a scanning electron microscope (SEM; Zeiss Supra 55; Carl Zeiss, Jena, Germany) were utilized to investigate the microstructure and surface morphology of the activated carbon. Functional group analysis of all the samples was conducted using an IS50 
FTIR spectrometer (Nicolet, Waltham, MA, USA) in the scanning range of 4000 to 400 $\mathrm{cm}^{-1}$. The phase analysis of activated carbons was performed using an X-ray diffractometer (XRD; Rigaku Ultima IV; Rigaku, Tokyo, Japan). Thermogravimetric analysis (TGA) of precursors was conducted to figure out the catalytic effects of potassium using a STA449/F3 simultaneous thermal analyzer (Netzsch, Selb, Germany). The element (C, H, $\mathrm{N}$, and $\mathrm{S}$ ) content of carbonaceous materials was evaluated by an elemental analyzer (EA; Vario-EL-III; Elementar, Hannover, Germany).

\section{RESULTS AND DISCUSSION}

\section{Essential Oils Extraction}

Yield of the essential oils

Figure 2 shows the yield of essential oils as a function of the extraction time. As expected, the essential oil extraction rate increased remarkably in the first $20 \mathrm{~min}$, and then slowly increased until the completion of the extraction process. In comparison to the increase in extraction rate of $2.4 \mathrm{wt} \%$ in $90 \mathrm{~min}$ for the raw citrus peels, the essential oil extraction rate increased to $3.7 \mathrm{wt} \%, 4.3 \mathrm{wt} \%$, and $6.2 \mathrm{wt} \%$ when the concentration of $\mathrm{K}_{2} \mathrm{CO}_{3}$ solution for the impregnation of citrus peels increased 50, 100, and $150 \mathrm{~g} / \mathrm{L}$, respectively. The results suggested that citrus peels impregnated with $\mathrm{K}_{2} \mathrm{CO}_{3}$ are of great benefit to essential oils extraction. This was due to the synergistic effect between the dehydration caused by steam vaporization and the breaking of bonds caused by $\mathrm{K}_{2} \mathrm{CO}_{3}$ pretreatment (Peng et al. 2010). This helped the essential oil that mainly is present in the oil sacs of plant cells to be released from the citrus peels. However, when more $\mathrm{K}_{2} \mathrm{CO}_{3}$ was added, the effect of covering the oil sacs by a large number of $\mathrm{K}_{2} \mathrm{CO}_{3}$ molecules was greater than that of destroying the oil sacs. Therefore, it was not surprising that the essential oils yield slightly decreased with a further increase in $\mathrm{K}_{2} \mathrm{CO}_{3}$ impregnation amount.

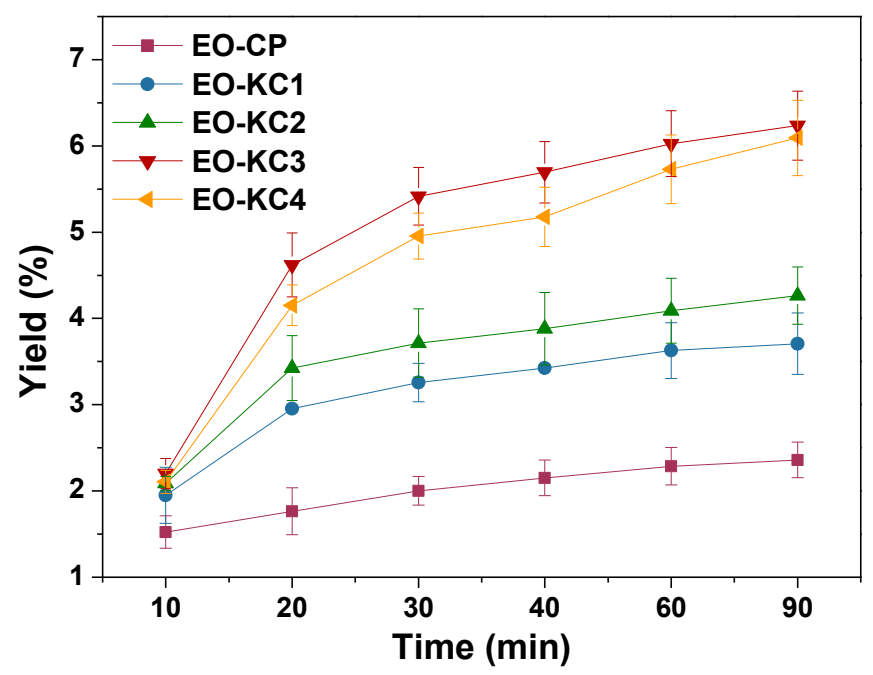

Fig. 2. Effect of the extraction time on essential oils yield

\section{Chemical compositions of the essential oils}

The main chemical compositions of essential oils extracted from the raw and pretreated citrus peels were identified by GC/MS (Table 2). It can be seen that D-limonene was the main chemical compound found in the essential oils, occupying more than $95 \%$ of 
the peak area, which was in agreement with that reported by Allaf et al. (2013). The chemical compositions of essential oils remained almost unchanged, which indicated that the quality of essential oils was not affected by the addition of $\mathrm{K}_{2} \mathrm{CO}_{3}$. In addition, $\mathrm{K}_{2} \mathrm{CO}_{3}$ was helpful for concentrating D-limonene in essential oils. This is an advantage for the high-value utilization of citrus peels, because these increased essential oils can also be directly used in areas that have already been developed in the perfume industry.

Table 2. Chemical Compositions of Essential Oils

\begin{tabular}{|c|c|c|c|c|c|c|}
\hline No. $^{*}$ & Components & \multicolumn{5}{|c|}{ Relative Peak Area (\%) } \\
\hline & & EO-CP & EO-KC1 & EO-KC2 & EO-KC3 & EO-KC4 \\
\hline 1 & D-limonene & 95.39 & 96.70 & 96.92 & 97.03 & 98.90 \\
\hline 2 & $\beta$-myrcene & 2.92 & 1.64 & 1.59 & 1.88 & 0.53 \\
\hline 3 & $\alpha-$-pinene & 0.78 & 0.37 & 0.42 & 0.54 & 0.22 \\
\hline 4 & $\beta$-phellandrene & 0.39 & 0.19 & 0.17 & 0.19 & 0.23 \\
\hline 5 & 3-carene & 0.38 & 0.14 & 0.15 & 0.15 & 0.12 \\
\hline
\end{tabular}

${ }^{*}$ Components listed in the order of relative peak area

Cytohistological analysis of the essential oils

Compared to the oil sacs of raw citrus peels (Fig. 3a), those of the citrus peels treated by steam distillation (Fig. 3b) were shrunken but still remained intact. This indicated that the fully extended cuticle that covered the oil sacs was so solid that the steam could not completely destroy the cuticle.
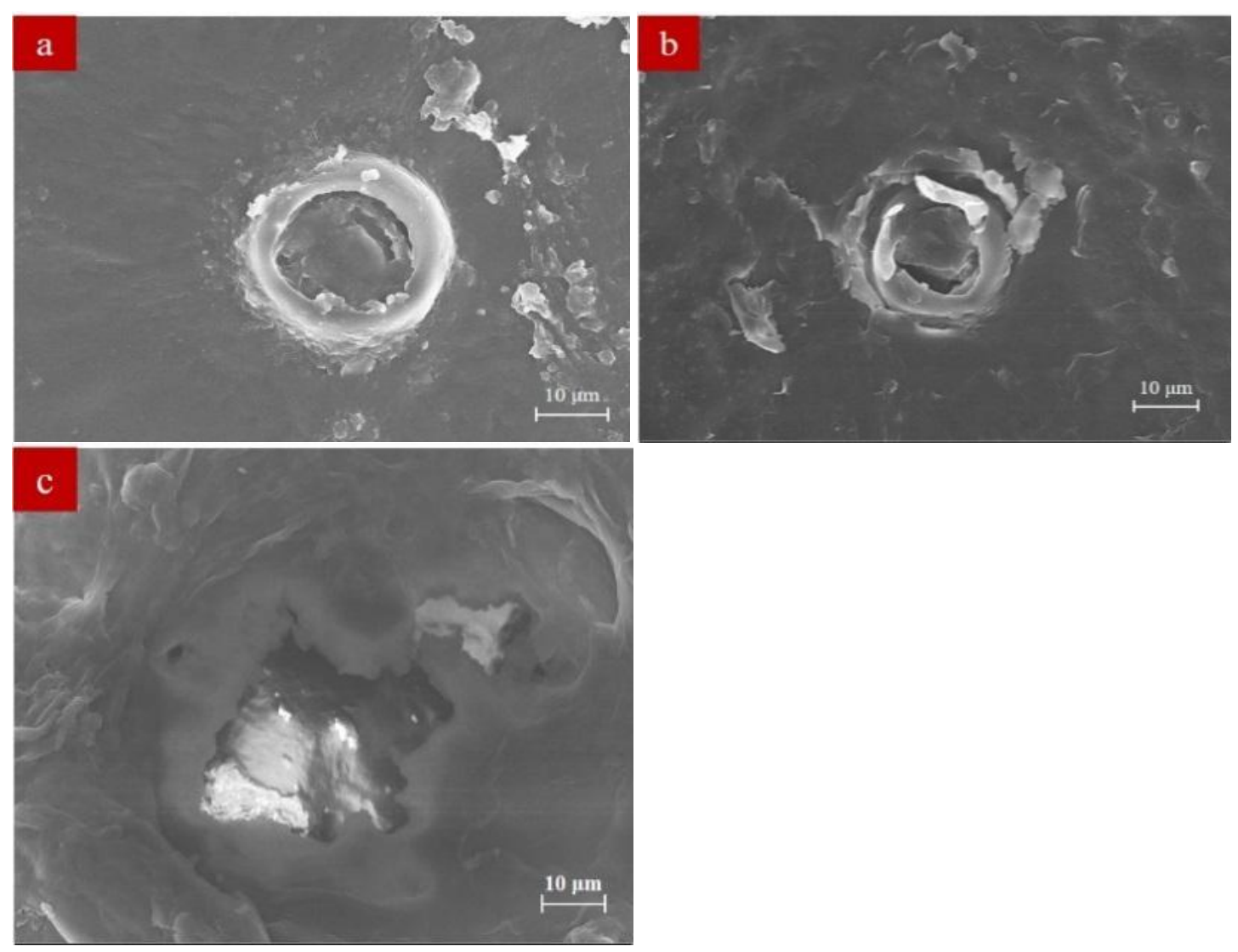

Fig. 3. SEM micrographs of (a) citrus peel, (b) CP-SD, and (c) CP-KC3 
However, when $\mathrm{K}_{2} \mathrm{CO}_{3}$ was added into citrus peels and then treated by steam distillation, the oil sacs were severely damaged to the extent of being completely cracked (Fig. 3c), which indicated that $\mathrm{K}_{2} \mathrm{CO}_{3}$ could lead to the disruption of the oil sac of citrus peels, and thus increased the yield of essential oils as observed in Fig. 2. Ming et al. (2016) reported a similar phenomenon. They studied the extraction of essential oils from pine sawdust and found that the glands of pine sawdust are completely disrupted in the process of steam distillation due to the use of alkali metal oxide.

\section{Preparation of the Activated Carbons}

Thermal degradation behavior

To study the effect of $\mathrm{K}_{2} \mathrm{CO}_{3}$ on the carbonizing process of citrus peels, the thermal degradation of raw and pretreated citrus peels was analyzed using a thermogravimetric (TG) analyzer. It can be seen from Fig. $4 \mathrm{a}$ that the TG profiles of all samples displayed similar trends, indicating that the thermal degradation of citrus peels would not be affected by the presence of $\mathrm{K}_{2} \mathrm{CO}_{3}$.
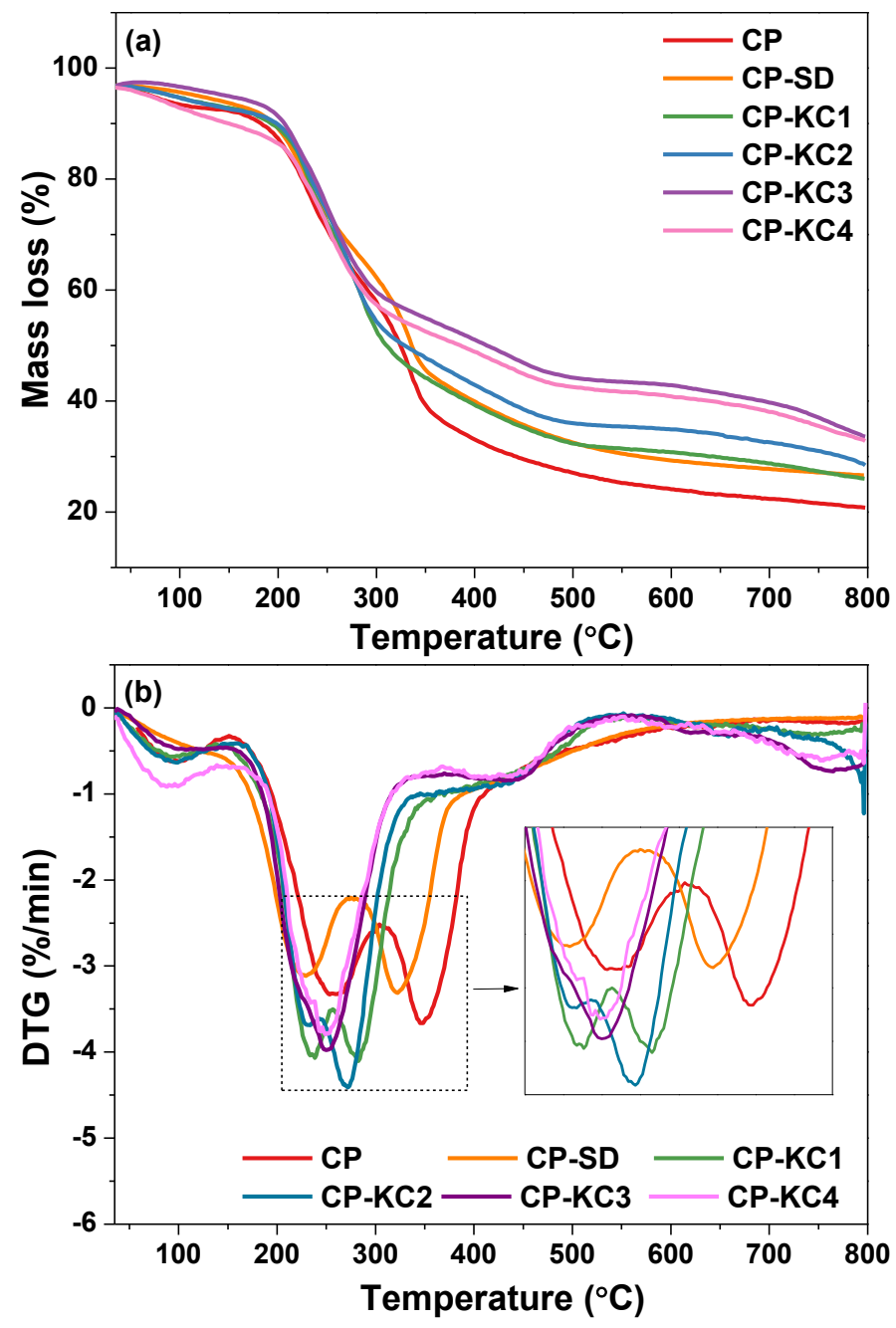

Fig. 4. (a) TG curves and (b) DTG curves of the precursors and activated carbons 
Compared to the sharp weight loss of citrus peels, the weight loss of the citrus peel pretreated with the $\mathrm{K}_{2} \mathrm{CO}_{3}$ solution was relatively mild. On the one hand, peels impregnated with more $\mathrm{K}_{2} \mathrm{CO}_{3}$ may retain more residual potassium salt. On the other hand, this may have been because the volatiles derived from citrus peel were converted to the solid char under the catalysis of $\mathrm{K}_{2} \mathrm{CO}_{3}$. It is not surprising that potassium salt is always regarded as an effective catalyst for favoring the secondary cracking of the volatiles (Rutkowski 2011). As shown in Fig. 4b, the first stage was found at approximately 40 to $160{ }^{\circ} \mathrm{C}$ for all of the samples, which was attributed to the loss of physisorbed water. A total of two differential thermal gravity (DTG) peaks at $258.1{ }^{\circ} \mathrm{C}$ and $349.5{ }^{\circ} \mathrm{C}$ were observed for the thermal degradation of raw citrus peels. However, these two peaks gradually merged into the one at a relatively low temperature of $246.0{ }^{\circ} \mathrm{C}$ with increased $\mathrm{K}_{2} \mathrm{CO}_{3}$ content. According to Yang et al. (2006), adding $\mathrm{K}_{2} \mathrm{CO}_{3}$ enhanced the pyrolysis of cellulose by shifting the pyrolysis reactions to a lower temperature range. Thus, the two peaks belonging to the thermal degradation of the pretreated citrus peels became overlapped.

\section{Products in the carbonization process}

The products in the carbonization process were analyzed when the carbonization temperature was fixed at $800{ }^{\circ} \mathrm{C}$ with the heating rate of $10{ }^{\circ} \mathrm{C} / \mathrm{min}$. Compared to the $27.69 \%$ yield from the carbonized citrus peels, the activated carbon yield decreased to $13.44 \%$ for CP-KC4 (Fig. 5a). It can also be seen that gas production was predominant, even for $\mathrm{CP}-\mathrm{KC} 1$, which contained the lowest $\mathrm{K}_{2} \mathrm{CO}_{3}$ content. Wang et al. (2010) also reported that gas production increased with $\mathrm{K}_{2} \mathrm{CO}_{3}$ addition during the pyrolysis processing of pine sawdust. The lower activated carbon yield and higher gas production was caused by severe catalyzation of the cross-linking reactions by $\mathrm{K}_{2} \mathrm{CO}_{3}$. Figure $5 \mathrm{~b}$ shows the concentrations of gases produced during the carbonization process. The relative content of CO reached $80.8 \%$ for the carbonization of raw citrus peels, which increased to approximately $92.3 \%$ for all of the pretreated citrus peels. This can be explained by the fact that the unstable oxygenates of the volatiles underwent secondary cracking and generated much more $\mathrm{CO}$ in the gaseous phase ( $\mathrm{Li}$ et al. 2014). Compared to the lower content of phenolic compounds obtained from the carbonization of raw citrus peels, the phenolic content obtained from the pretreated citrus peels increased remarkably, while the content of ketones was reduced (Fig. 5c). This indicated that the activating agent of $\mathrm{K}_{2} \mathrm{CO}_{3}$ strengthened the degradation of lignin by breaking the linkage among the phenolic compounds.

\section{Characteristic of the Activated Carbons}

Surface area and porosity

The textural properties and pore size distributions of the activated carbons were analyzed. As expected, the BET surface area of the activated carbons increased from 872 to $1846 \mathrm{~m}^{2} / \mathrm{g}$ when the concentration of $\mathrm{K}_{2} \mathrm{CO}_{3}$ solution for citrus peels impregnation increased from 50 to $200 \mathrm{~g} / \mathrm{L}$ (Table 3), respectively. Compared to AC-KC3 of $1701 \mathrm{~m}^{2} / \mathrm{g}$, a higher $S_{\mathrm{BET}}$ of $2285 \mathrm{~m}^{2} / \mathrm{g}$ was observed for AC-KC-NP. In the extraction process of essential oils, part of the $\mathrm{K}_{2} \mathrm{CO}_{3}$ solution remained in the flask because of the reflux effect of steam, which resulted in less impregnation by $\mathrm{K}_{2} \mathrm{CO}_{3}$ of AC-KC3 than of AC-KC-NP. It was noted that the $S_{\mathrm{BET}}$ of Char-SD was higher than that of Char-CP, which indicated that the treatment of steam distillation was advantageous in the carbonization step and gave rise to the formation of pores. This may have been due to the release of volatiles and damaging of the partial thin pore walls under steam distillation. 

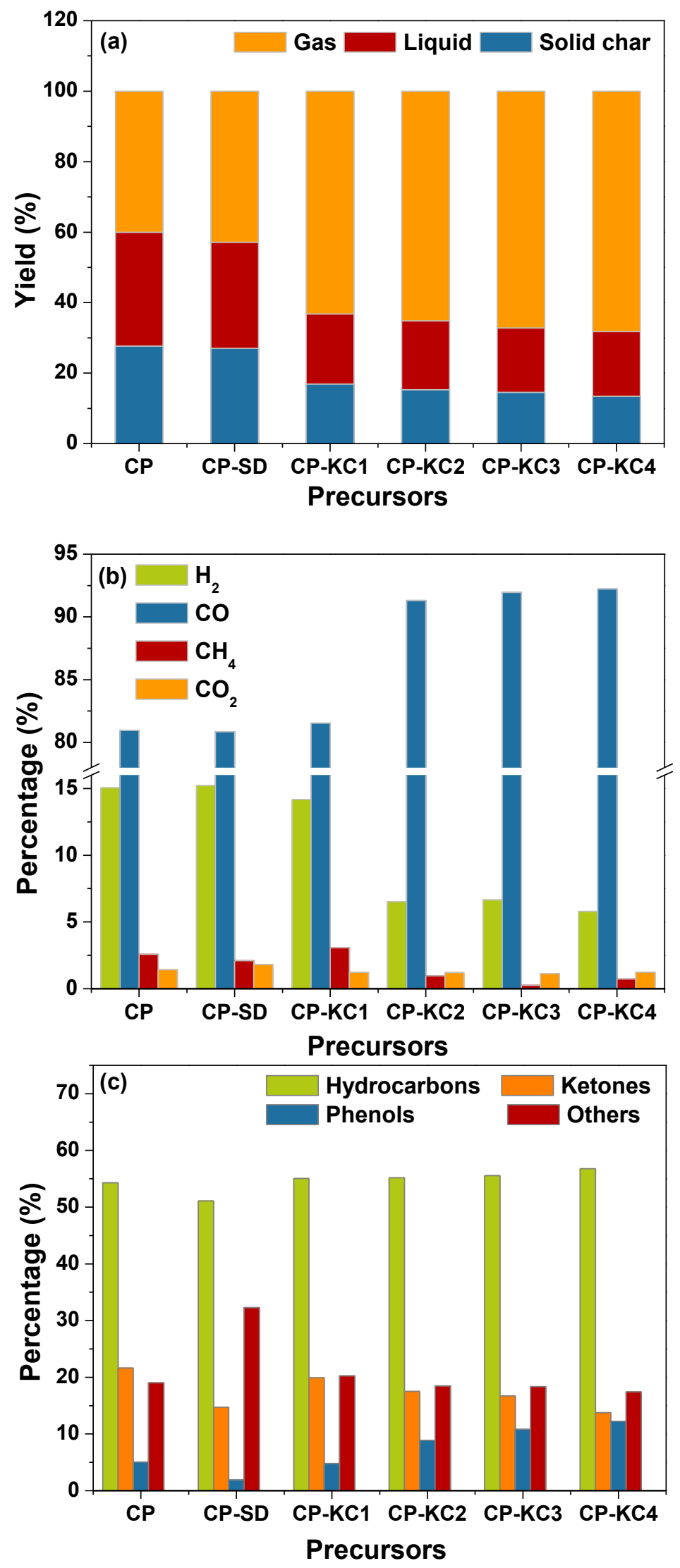

Fig. 5. Overall analysis of the products: (a) the distribution of products; (b) the composition of gases released; and (c) the composition of liquid phase 
Table 3 also shows the microporosity $\left(V_{\text {micro }} / V_{\mathrm{t}}\right)$ of chars and activated carbons prepared in this study. The microporosity of the activated carbons decreased with increasing $\mathrm{K}_{2} \mathrm{CO}_{3}$ dose, which was because the oxygen atoms of the carbonate ions strongly etched away the exposed carbons. Compared to the micropore volume ( $\left.V_{\text {micro }}\right)$ of $0.012 \mathrm{~cm}^{3} / \mathrm{g}$ for Char-CP, a micropore volume of $0.027 \mathrm{~cm}^{3} / \mathrm{g}$ was reached for Char-SD. However, the total pore volume $\left(V_{\mathrm{t}}\right)$ only slightly increased to $0.031 \mathrm{~cm}^{3} / \mathrm{g}$ for Char-SD, resulting in Char-SD having the highest microporosity among the prepared samples. However, Foo et al. (2012) reported that the prepared activated carbon showed abundant mesoporous structures using orange peel as the precursor with $\mathrm{K}_{2} \mathrm{CO}_{3}$ activating agent. This indicates that the distillation pretreatment may be beneficial to improving the microporosity of samples.

Table 3. Properties of the Chars and Activated Carbons Derived From Citrus Peels

\begin{tabular}{|c|c|c|c|c|c|}
\hline Samples & $S_{\text {BET }}\left(\mathrm{m}^{2} / \mathrm{g}\right)$ & $V_{\mathrm{t}}\left(\mathrm{cm}^{3} / \mathrm{g}\right)$ & $V_{\text {micro }}\left(\mathrm{cm}^{3} / \mathrm{g}\right)$ & $V_{\text {micro }} / V_{\mathrm{t}}(\%)$ & $D_{\mathrm{p}}(\mathrm{nm})$ \\
\hline Char-CP & 43 & 0.026 & 0.012 & 46.15 & 2.42 \\
\hline Char-SD & 70 & 0.031 & 0.027 & 87.10 & 1.71 \\
\hline AC-KC1 & 872 & 0.454 & 0.368 & 81.05 & 2.06 \\
\hline AC-KC2 & 1376 & 0.622 & 0.504 & 80.98 & 1.80 \\
\hline AC-KC3 & 1701 & 0.731 & 0.590 & 80.82 & 1.90 \\
\hline AC-KC4 & 1846 & 0.904 & 0.723 & 80.02 & 1.96 \\
\hline AC-KC-NP & 2285 & 1.339 & 0.451 & 33.67 & 2.34 \\
\hline
\end{tabular}

As shown in Fig. 6a, the $\mathrm{N}_{2}$ adsorption-desorption isotherm at $77 \mathrm{~K}$ exhibited a sharp rise, followed by a gradual approach to a plateau, and finally a small rise for all cases. These curves belong to types I and IV isotherms based on International Union of Pure and Applied Chemistry (IUPAC) classification (Donohue and Aranovich 1998), which indicated that the carbon materials mainly contained both micropores and mesopores. The pore size distribution curves in Fig. $6 \mathrm{~b}$ confirmed the formation of well-developed microporosity in activated carbons because the pore size was mainly distributed in the range of 1 to $3 \mathrm{~nm}$.
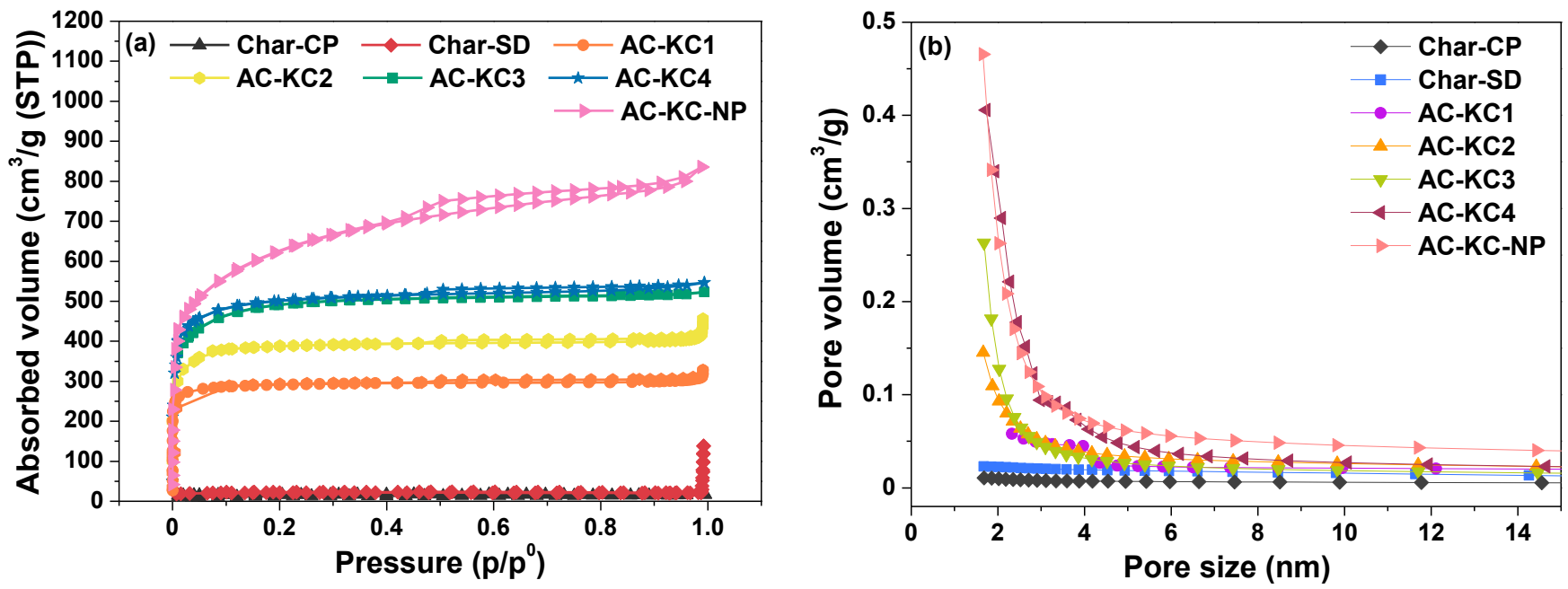

Fig. 6. (a) $\mathrm{N}_{2}$ adsorption-desorption isotherms; and (b) pore size distributions of activated carbons 


\section{SEM/TEM observation}

Figure 7 shows the morphology of prepared samples via SEM/TEM. The surface of char derived from the carbonization of raw citrus peels was relatively smooth (Fig. 7a), and no distinct pores were observed. However, the surface of Char-SD showed more cracks (Fig. 7b), indicating that steam distillation was helpful for increasing the surface area. An irregular and heterogeneous surface morphology with a well-developed porous structure was observed from the micrograph of AC-KC-NP (Fig. 7c) demonstrating that the existing pores were widened and more new pores were produced due to the activating effect of $\mathrm{K}_{2} \mathrm{CO}_{3}$. The microstructures of $\mathrm{AC}-\mathrm{KC} 3$ and $\mathrm{AC}-\mathrm{KC} 4$ were also analyzed using TEM. Compared to the surface of $\mathrm{AC}-\mathrm{KC} 3$ (inset of Fig. 7d), more pores were observed in the surface of AC-KC4 (inset of Fig. 7e), indicating that the quality of activated carbons was improved when more $\mathrm{K}_{2} \mathrm{CO}_{3}$ activating agent was used in the process of essential oils extraction.
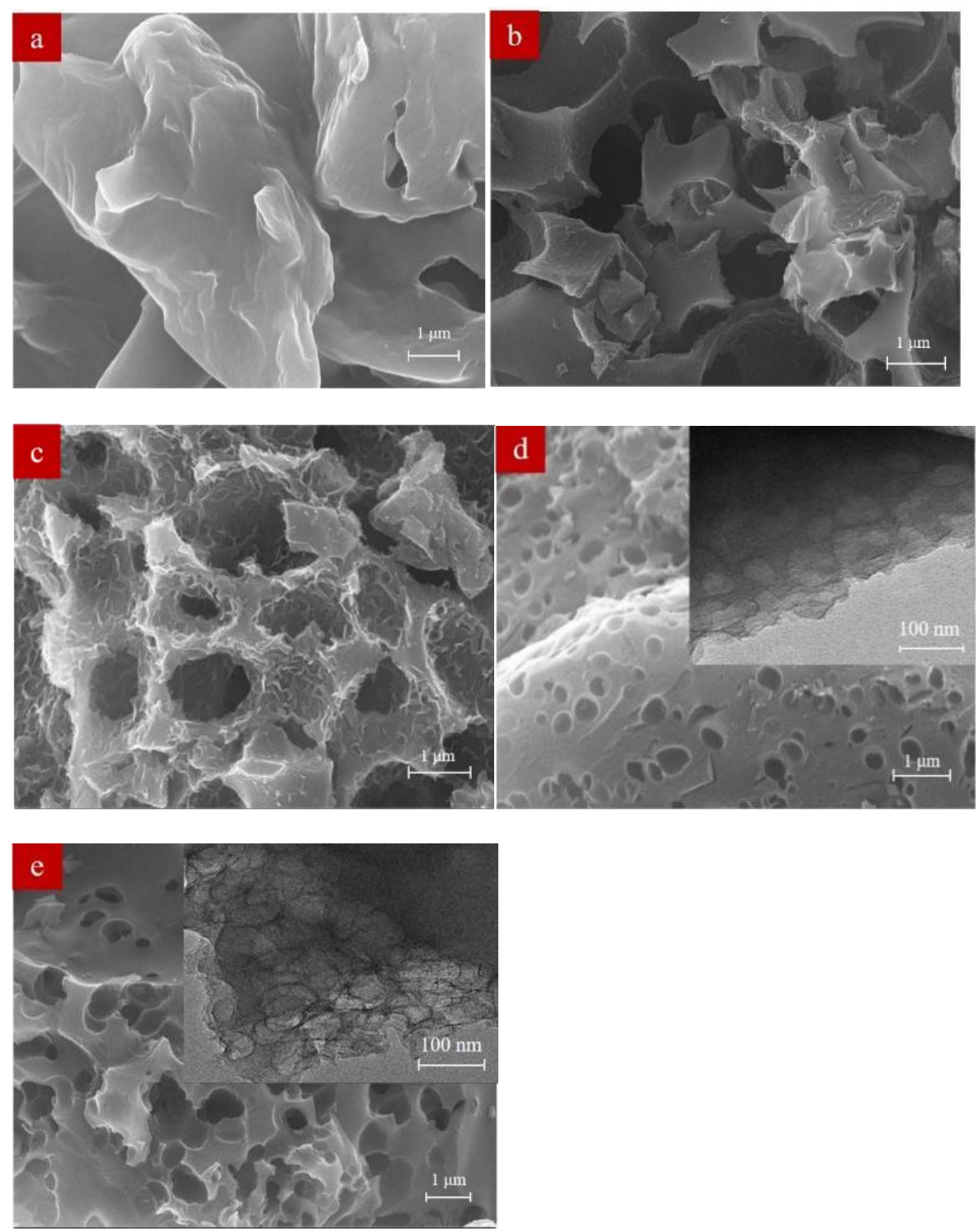

Fig. 7. SEM micrographs of (a) Char-CP, (b) Char-SD, and (c) AC-KC-NP; SEM/TEM micrographs of (d) AC-KC3 and (e) AC-KC4 


\section{FTIR}

FTIR spectroscopy was used to determine the change in functional groups between the raw citrus peels and prepared activated carbons. The absorption peak that appeared at $3415 \mathrm{~cm}^{-1}$ was attributed to the $\mathrm{O}-\mathrm{H}$ stretching vibration of the hydroxyl functional groups, while the peak at $2926 \mathrm{~cm}^{-1}$ was attributed to the presence of alkyl C-H stretching, and the peak at $1066 \mathrm{~cm}^{-1}$ was attributed to the $\mathrm{C}-\mathrm{O}$ symmetric stretching vibration in the aromatic ring. As shown in Fig. 8a, the band at $1740 \mathrm{~cm}^{-1}$ was attributed to the $\mathrm{C}=\mathrm{O}$ stretching vibration of the carboxyl groups, which completely disappeared on the surface of the activated carbons (Fig. 8b). Meanwhile, the band at $1630 \mathrm{~cm}^{-1}$, attributed to the $\mathrm{C}=\mathrm{O}$ stretching vibration of pectin, appeared in the citrus peels, which became weaker in the spectrum of activated carbons. This might have been due to the activating agent $\mathrm{K}_{2} \mathrm{CO}_{3}$ initiating the bond cleavage through the dehydration reactions. Compared to the spectrum of citrus peels, the broad region of overlapping bands in the range 1500 to $1200 \mathrm{~cm}^{-1}$ became sharp in all of the activated carbons, which indicated the oxidative degradation of the aromatic ring during the carbonization process.
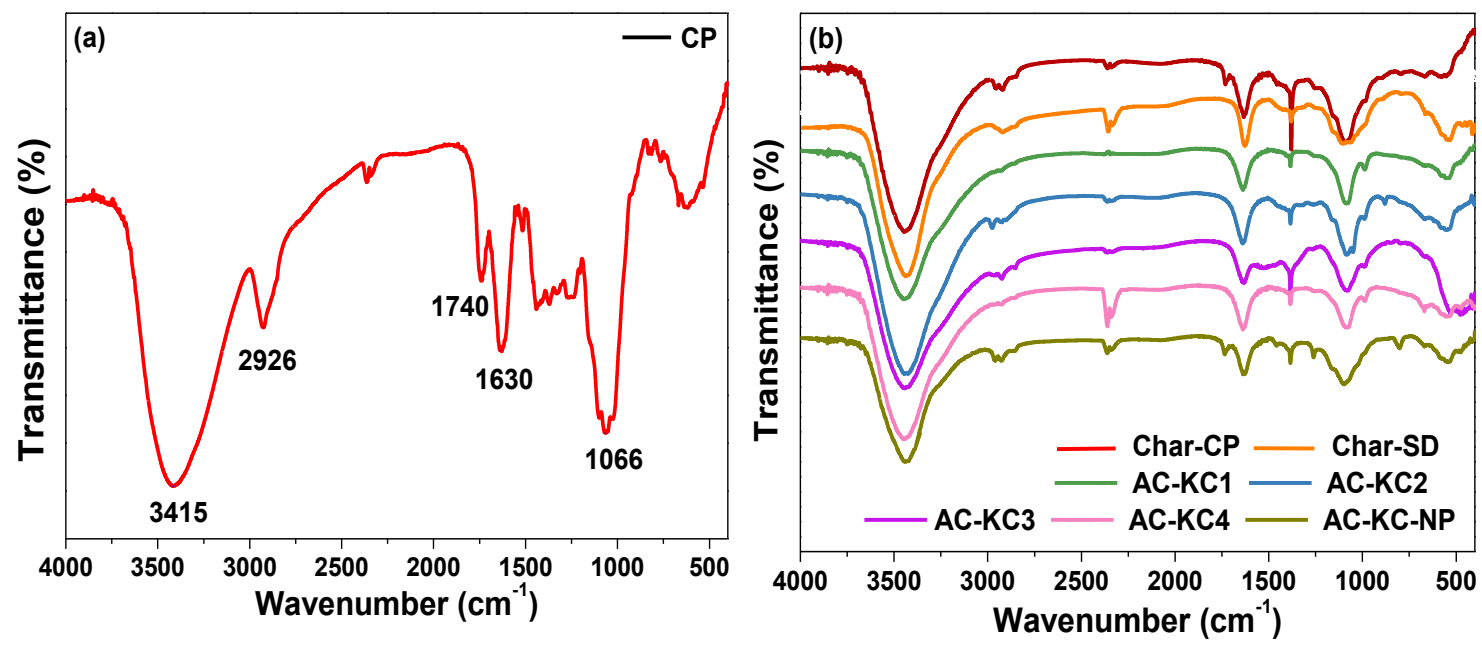

Fig. 8. FTIR spectra of (a) raw citrus peels and (b) chars and activated carbons

$X R D$

To obtain additional insights into the chemical composition of the prepared activated carbons, XRD measurements were recorded. Figure 9 shows the XRD diffraction patterns of Char-CP, Char-SD, AC-KCs, and AC-KC-NP. The XRD patterns for all the chars and activated carbons displayed two broad diffraction peaks around $2 \theta=23^{\circ}$ and $43^{\circ}$, which corresponded to the (002) and (100) planes, respectively. This indicated that there were some microcrystals with turbostratic graphite structure in the prepared activated carbons. Using Bragg's law, the interlayer spacing $d_{002}$ value was calculated for Char-CP and all of the activated carbons. The values of Char-CP and activated carbons were 0.19 and $0.21 \mathrm{~nm}$, respectively, suggesting that the turbostratic degree of the prepared activated carbons was more apparent. This behavior contributed to the expansion of inter-planar distance inside the graphitic microcrystallines of activated carbons, which produced new pores and enlarged the existing pores, corresponding to larger surface area and pore width. Therefore, it was verified that the disordered activated carbons prepared from citrus peels exhibited better porosity, and consequently achieved a higher surface area. 


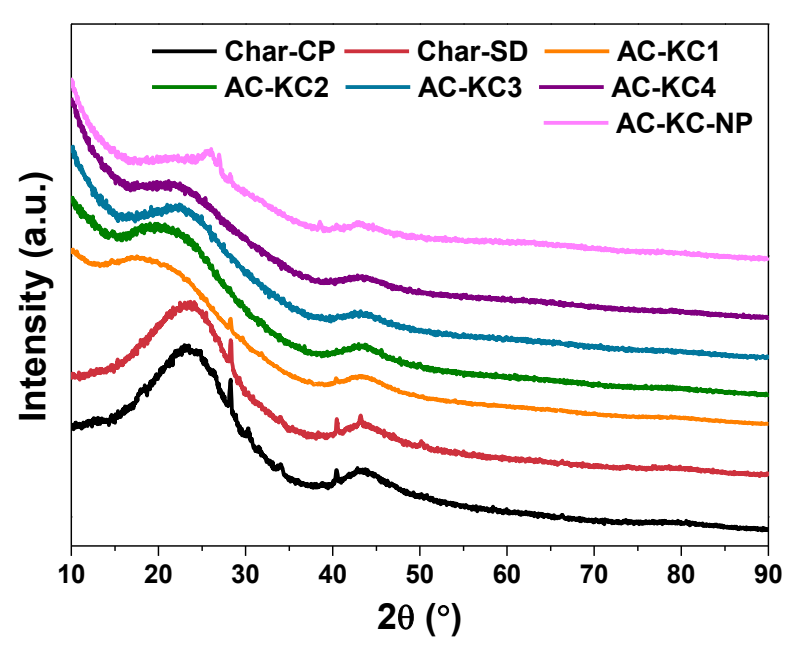

Fig. 9. XRD patterns of the activated carbons

\section{CONCLUSIONS}

A type of industrial waste, citrus peel, was demonstrated to be a valuable resource for simultaneous essential oil extraction and activated carbon preparation. Compared to the $2.4 \mathrm{wt} \%$ extraction rate of essential oil in a regular steam distillation, a $6.2 \mathrm{wt} \%$ extraction rate was achieved when citrus peel was pretreated by a $\mathrm{K}_{2} \mathrm{CO}_{3}$ solution. The oil sacs were disrupted severely due to the cleavage of bonds induced by $\mathrm{K}_{2} \mathrm{CO}_{3}$. The solid residue collected after essential oil extraction was further used as the precursor for activated carbons. The specific surface area of activated carbons reached up to $1846 \mathrm{~m}^{2} / \mathrm{g}$. The obtained activated carbon exhibited a highly developed microporous structure.

\section{ACKNOWLEDGMENTS}

The authors are grateful for the support of the President Foundation of Xiamen University (Grant No. 20720150095) and the Energy development Foundation of College of Energy, Xiamen University (Grant No. 2017NYFZ02).

\section{REFERENCES CITED}

Acar, Ü., Kesbiç, O. S., Y1lmaz, S., Gültepe, N., and Türker, A. (2015). “Evaluation of the effects of essential oil extracted from sweet orange peel (Citrus sinensis) on growth rate of tilapia (Oreochromis mossambicus) and possible disease resistance against Streptococcus iniae," Aquaculture 437(3), 282-286. DOI: 10.1016/j.aquaculture.2014.12.015

Allaf, T., Tomao, V., Besombes, C., and Chemat, F. (2013). "Thermal and mechanical intensification of essential oil extraction from orange peel via instant autovaporization," Chem. Eng. Process. 72(10), 24-30. DOI: 10.1016/j.cep.2013.06.005 
Bustamante, J., Stempvoort, S. V., García-Gallarreta, M., Houghton, J. A., Briers, H. K., Budarin, V. L., Matharu, A. S., and Clark, J. H. (2016). "Microwave assisted hydrodistillation of essential oils from wet citrus peel waste," J. Clean. Prod. 137(28), 598605. DOI: 10.1016/j.jclepro.2016.07.108

Dhelipan, M., Arunchander, A., Sahu, A. K., and Kalpana, D. (2017). "Activated carbon from orange peels as supercapacitor electrode and catalyst support for oxygen reduction reaction in proton exchange membrane fuel cell," J. Saudi Chem. Soc. 21(4), 487-494. DOI: 10.1016/j.jscs.2016.12.003

Donohue, M. D., and Aranovich, G. L. (1998). "Classification of Gibbs adsorption isotherms," Adv. Colloid. Interfac. 76-77, 137-152. DOI: 10.1016/S00018686(98)00044-X

Dupont, C., Jacob, S., Marrakchy K. O., Hognone, C., Grateau, M., Labalette, F., and Perez, D. D. S. (2016). "How inorganic elements of biomass influence char steam gasification kinetics,” Energy 109(16), 430-435. DOI: 10.1016/j.energy.2016.04.094

Farhat, A., Fabiano-Tixier, A., Maataoui, M. E., Maingonnat, J., Romdhane, M., and Chemat, F. (2011). "Microwave steam diffusion for extraction of essential oil from orange peel: Kinetic data, extract's global yield and mechanism," Food Chem. 125(1), 255-261. DOI: 10.1016/j.foodchem.2010.07.110

Foo, K. Y., and Hameed, B. H. (2012). "Factors affecting the carbon yield and adsorption capability of the mangosteen peel activated carbon prepared by microwave assisted $\mathrm{K}_{2} \mathrm{CO}_{3}$ activation," Chem. Eng. J. 180(2), 66-74. DOI: 10.1016/j.cej.2011.11.002

Ledesma-Escobar, C. A., and Luque de Castro, M. D. (2014). "Towards a comprehensive exploitation of citrus," Trends Food Sci. Tech. 39(1), 63-75. DOI:

10.1016/j.tifs.2014.07.002

Li, M., and Xiao, R. (2019). "Preparation of a dual pore structure activated carbon from rice husk char as an adsorbent for $\mathrm{CO}_{2}$ capture," Fuel Process. Technol. 186(4), 3539. DOI: 10.1016/j.fuproc.2018.12.015

Li, S., Chen, X. L., Liu, A. B., Guang, L. W., and Yu, S. (2014). "Study on co-pyrolysis characteristics of rice straw and Shenfu bituminous coal blends in a fixed bed reactor," Bioresource Technol. 155(5), 252-257. DOI: 10.1016/j.biortech.2013.12.119

Lohrasbi, M., Pourbafrani, M., Niklasson, C., and Taherzadehc, M. J. (2010). "Process design and economic analysis of a citrus waste biorefinery with biofuels and limonene as products," Bioresource Technol. 101(19), 7382-7388. DOI: 10.1016/j.biortech.2010.04.078

Ming, Z. Q., Liu, Y. Q., Ye, Y. Y., Li, S. R., Zhao, Y. R., and Wang, D. (2016). "Study of a new combined method for pre-extraction of essential oils and catalytic fast pyrolysis of pine sawdust," Energy 116(23), 558-566. DOI: 10.1016/j.energy.2016.09.136

Mouahid, A., Dufour, C., and Badens, E. (2017). "Supercritical $\mathrm{CO}_{2}$ extraction from endemic Corsican plants: Comparison of oil composition and extraction yield with hydrodistillation method," J. $\mathrm{CO}_{2}$ Util. 20(4), 263-273. DOI: 10.1016/j.jcou.2017.06.003

Peng, X., Zhong, L. X., Ren, J. L., and Sun, R. C. (2010). "Laccase and alkali treatments of cellulose fibre: Surface lignin and its influences on fibre surface properties and interfacial behaviour of sisal fibre/phenolic resin composites," Compos. Part A- Appl. S. 41(12), 1848-1856. DOI: 10.1016/j.compositesa.2010.09.004

Romero-Cano, L. A., Gonzalez-Gutierrez, L. V., and Baldenegro-Perez, L. A. (2016). "Biosorbents prepared from citrus peels using instant controlled pressure drop for 
Cu(II) and phenol removal," Ind. Crop. Prod. 84(6), 344-349. DOI:

10.1016/j.indcrop.2016.02.027

Rutkowski, P. (2011). "Pyrolysis of cellulose, xylan and lignin with the $\mathrm{K}_{2} \mathrm{CO}_{3}$ and $\mathrm{ZnCl}_{2}$ addition for bio-oil production," Fuel Process. Technol. 92(3), 517-522. DOI:

10.1016/j.fuproc.2010.11.006

Santos, C. M., Dweck, J., Viotto, R. S., Rosa, A. H., and De Morais, L. C. (2015).

"Application of orange peel waste in the production of solid biofuels and biosorbents," Bioresource Technol. 196(22), 469-479. DOI:

10.1016/j.biortech.2015.07.114

Sharma, K., Mahato, N., Cho, M. H., and Lee, Y. R. (2017). "Converting citrus wastes into value-added products: Economic and environmentally friendly approaches," Nutrition 34(2), 29-46. DOI: 10.1016/j.nut.2016.09.006

Tovar, A. K., Godínez, L. A., Espejel, F., Ramírez-Zamora, R. M., and Robles, I. (2019). "Optimization of the integral valorization process for orange peel waste using a design of experiments approach: Production of high-quality pectin and activated carbon," Waste Manage. 85(3), 202-213. DOI: 10.1016/j.wasman.2018.12.029

Uysal, B., Sozmen, F., Aktas, O., Oksal, B. S., and Kose, E. O. (2011). "Essential oil composition and antibacterial activity of the grapefruit (Citrus paradisi. L) peel essential oils obtained by solvent-free microwave extraction: Comparison with hydrodistillation," Int. J. Food Sci. Tech. 46(7), 1455-1461. DOI: 10.1111/j.13652621.2011.02640.x

Xiao, H., Peng, H., Deng, S., Yang, X., Zhang, Y., and Li, Y. (2012). "Preparation of activated carbon from edible fungi residue by microwave assisted $\mathrm{K}_{2} \mathrm{CO}_{3}$ activation: Application in reactive black 5 adsorption from aqueous solution," Bioresource Technol. 111(9), 127-133. DOI: 10.1016/j.biortech.2012.02.054

Yang, H., Yan, R., Chen, H. P., Zheng, C. G., Lee, D. H., and Liang, D. T. (2006). "Influence of mineral matter on pyrolysis of palm oil wastes," Combust. Flame 146(4), 605-611. DOI: 10.1016/j.combustflame.2006.07.006

Yen, H. Y., and Lin, Y. C. (2017). "Green extraction of cymbopogon citrus essential oil by solar energy," Ind. Crop. Prod. 108(14), 716-721. DOI: 10.1016/j.indcrop.2017.07.039

Wang, Z., Wang, F., Cao, J. Q., and Wang, J. (2010). "Pyrolysis of pine wood in a slowly heating fixed-bed reactor: Potassium carbonate versus calcium hydroxide as a catalyst," Fuel Process. Technol. 91(8), 942-950. DOI: 10.1016/j.fuproc.2009.09.015

Article submitted: December 18, 2018; Peer review completed: March 9, 2019; Revised version received: March 15, 2019; Accepted: March 16, 2019; Published: March 27, 2019.

DOI: 10.15376/biores.14.2.3899-3913 